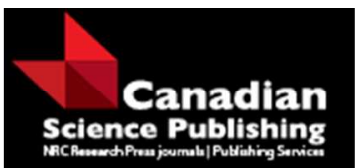

Canadian Journal of Forest Research Revue canadienne de recherche forestière

\title{
Fire effects on acorn production are consistent with the stored resource hypothesis for masting behavior
}

\begin{tabular}{|r|l|}
\hline Journal: & Canadian Journal of Forest Research \\
\hline Manuscript ID & cjfr-2015-0227.R1 \\
\hline Manuscript Type: & Article \\
\hline Date Submitted by the Author: & 01-Sep-2015 \\
\hline Complete List of Authors: & $\begin{array}{l}\text { Funk, Kyle; University of Nebraska - Lincoln, School of Biological Sciences } \\
\text { Koenig, Walter; Cornell University } \\
\text { Knops, Johannes; School of Biological Sciences }\end{array}$ \\
\hline Keyword: & masting, acorn production, resource allocation, fire, Quercus \\
\hline
\end{tabular}

\section{SCHOLARONE \\ Manuscripts}


Fire effects on acorn production are consistent with the stored resource hypothesis for masting behavior

Kyle A. Funk, Walter D. Koenig, Johannes M. H. Knops

K.A. Funk (sckfunk@gmail.com) and J.M.H. Knops (jknops2@unl.edu). School of Biological Sciences, University of Nebraska - Lincoln, Lincoln, NE, 68588 USA

W.D. Koenig (wdk4@cornell.edu). Cornell Lab of Ornithology, Ithaca, NY, 14850 USA and Department of Neurobiology and Behavior, Cornell University, Ithaca, NY, 14853 USA 


\begin{abstract}
Highly variable patterns of seed production ("masting") have been hypothesized to be driven by internal dynamics of resource storage and depletion. This hypothesis predicts that if seed production is artificially reduced, the availability of unused stored resources should result in subsequent enhancement of the seed crop. We tested this prediction in two oak species with contrasting patterns of annual seed production (highly variable and relatively constant) by means of controlled burns at various frequencies over a 17-year period. We found that controlled burns reduced acorn production by both species in the year of the burn. In the species with relatively constant productivity, acorn production returned to baseline levels in the year following a burn, but in the highly variable species, acorn production significantly increased the year following a burn. These results support a key prediction of the stored resource hypothesis by means of a long-term experimental test in wild tree populations.
\end{abstract}

Key words: Masting, acorn production, resource allocation, fire, Quercus. 


\section{Introduction}

2 Many long-lived species of plants show highly variable patterns of seed production from

3 year to year (Kelly and Sork 2002; Silvertown 1980). When intermittent episodes of intense

4 reproduction are synchronized across a population ("masting" behavior), evidence suggests that a

5 fitness advantage is conferred via increased fertilization rates and/or decreased seed predation

6 (Koenig et al. 1994b; Kon et al. 2005; Silvertown 1980). However, the proximate mechanisms

7 that produce masting patterns in wild plant populations are only beginning to be understood.

8 The cost of producing a large crop of fruits or cones, in terms of carbohydrates and

9 mineral nutrients, can be considerable (Kozlowski and Keller 1966). Because of these substantial

10 costs, it has been hypothesized that within a given year, masting plants are faced with a resource

11 allocation trade-off between growth and reproduction (Norton and Kelly 1988; Sork et al. 1993).

12 While negative correlations between growth and reproduction are documented in some masting

13 species (Harper 1977; Koenig and Knops 1998), it has also been found that such relationships

14 can be confounded by covariation with a third variable (Roff 2002; Knops et al. 2007). This third

15 variable can be the environment affecting growth and reproduction in opposite ways, or it can be

16 storage of resources, which potentially drive trade-offs between life-history characters across

17 and/or within years.

18 Here we define "resource storage" as resources that accumulate in the plant and can be

19 mobilized to support future biosynthesis (Chapin et al. 1990). Examples of storage compounds

20 include carbohydrates, lipids, and mineral nutrients. Resource storage is hypothesized to play a

21 role in the mechanism for masting as follows: producing a large crop of seeds demands nutrients

22 that depletes a plant's reserves, which then require more than one growing season to re-

23 accumulate. We refer to this as the "stored resource hypothesis." 
24 While the stored resource hypothesis has received considerable theoretical support

25 (Crone et al. 2005; Isagi et al. 1997; Satake and Iwasa 2002; Satake and Bjornstad 2008),

26 empirical evidence has been mixed. A key prediction of the hypothesis is that resources should

27 accumulate between mast years and be depleted following a masting event. This prediction has

28 been supported in some studies (Miyazaki et al. 2002; Crone et al. 2009) but not others (Ichie et

29 al. 2005, 2013; Hoch et al. 2013) when carbohydrates were the currency of storage investigated

30 (Miyazaki 2013). There has been more consistent support when mineral nutrients have been

31 examined as the stored resource, but experimental work in this area is still rare (Crone and Rapp

32 2014). Uncertainty surrounding the stored resource hypothesis lies partly in the limited temporal

33 scale of inquiry, as most studies examine only one or two large reproductive efforts, while long-

34 term experiments are uncommon, with some notable exceptions (Smaill et al. 2011; Rapp and

35 Crone 2015).

36 Here we take advantage of a long-term program of prescribed burns to test a key

37 prediction of the stored resource hypothesis: reducing or eliminating reproduction in one year

38 results in a surplus of stored resources driving enhanced reproduction in a subsequent year.

39 Prescribed burns conducted during spring have been found to reduce acorn production in that

40 season, at least partly due to damage to flowers and floral primordia (Peter et al. 2011). Thus,

41 burns are expected to reduce investment in current reproduction. Concurrently, burns add a

42 transient pulse of mineral nutrients to the soil (White et al. 1973; Schoch and Binkley 1986;

43 Boerner et al. 1988; Gray and Dighton 2006). Both of these effects are expected to increase

44 resource availability to the trees and therefore increase reproduction in the subsequent year via

45 the stored resource hypothesis.

46 We used prescribed burning to test the role of stored resources in two species of oaks 
47 (family Fagaceae, genus Quercus) differing in their masting patterns. One species (bur oak,

48 Quercus macrocarpa Michx.) exhibits highly variable annual seed production (masting) while

49 the other (pin oak, Q. ellipsoidalis E.J. Hill) does not. Comparing the effects of fire (and reduced

50 seed production) between two species with contrasting patterns of seed production provides a

51 rigorous test of the stored resource hypothesis. While costs of reproduction are very common in

52 plants (Obeso 2002), the stored resource hypothesis predicts that they manifest differently in

53 masting and non-masting species. In masting species, factors increasing the costs of reproduction

54 in one year are likely to affect reproduction in future years, whereas in non-masting species such

55 costs are likely to affect other functions, such as growth or defense, in the same year (Crone and

56 Rapp 2014). Therefore, we predicted that prescribed burns, by curtailing investment in

57 reproduction during the year of the treatment, would enhance reproduction the following year in

58 the masting species where reproductive investment involves significant resource storage and

59 depletion, but would have little or no effect in the non-masting species. In other words, if internal

60 resource dynamics are controlling patterns of masting, then burns should reduce acorn

61 production in both species the year of the burn, but should significantly enhance acorn

62 production in the following year only in bur oaks (the masting species).

63

\section{Materials and methods}

65 We measured annual acorn production of 90 individual bur oaks and 89 individual pin

66 oaks at Cedar Creek Ecosystem Science Reserve in Bethel, Minnesota, USA. Bur oak is a

67 member of the white oak section of the genus (section Quercus), has acorns that mature in one

68 growing season (a "1-year" species), and produces a highly variable acorn crop (population

69 coefficient of variation $\left[\mathrm{CV}_{\mathrm{p}}\right]=0.70$, Fig. 1) that is within the typical range for masting species 
70 (Koenig et al. 2003). Diameter at breast height (DBH), as measured in 1995, for the bur oaks

71 study population ranged from $11.0 \mathrm{~cm}$ to $68.8 \mathrm{~cm}$, with a mean \pm standard deviation (SD) of 34.7

$72 \pm 11.5 \mathrm{~cm}$. Pin oak is a member of the red oak section of the genus (section Lobatae), requires

73 two growing seasons to mature acorns (a "2-year" species), and produces a relatively constant

74 acorn crop $\left(\mathrm{CV}_{\mathrm{p}}=0.28\right.$, Fig. 1$)$. $\mathrm{DBH}$ in 1995 for the pin oak population ranged from $17.0 \mathrm{~cm}$ to

$7589.0 \mathrm{~cm}$, with a mean $\pm \mathrm{SD}$ of $44.3 \pm 14.9 \mathrm{~cm}$. During the study, pin oak experienced high fire-

76 induced mortality with 26 (29\%) individuals dying. Mortality of bur oak was substantially less,

77 with only six individuals (7\%) dying. Dead individuals were not replaced during the study.

$78 \quad$ Prescribed burning was initiated at Cedar Creek in 1964 to restore and maintain oak

79 savannah vegetation and to investigate the effects of fire frequency on vegetation (Peterson and

80 Reich 2001). The various treatments were spread across 19 burn units varying in size from 2.4 to

8130 ha. We counted acorns on trees distributed evenly among six sites that experienced fire

82 frequencies ranging from 0 to 12 fires during the 17-year study (Table 1). These particular sites

83 were selected to represent two of the lowest fire frequencies, two intermediate fire frequencies,

84 and two of the highest fire frequencies. Except in two cases, prescribed burns occurred in April

85 or May after snowmelt but before leaves appeared on the oaks. In 2001, at two sites, there were

86 prescribed burns in October. We treated these cases as "not burned" sites, but analyses

87 considering these cases as "burned" sites did not alter the results. Fire behavior varied with

88 weather conditions and fuel load, but was generally of low intensity with mean flame lengths $<1$

$89 \mathrm{~m}$ (Peterson and Reich 2001).

90 Acorn production by each tree was measured every August or late July from 1995 to

912011 using visual surveys in which two observers scanned different parts of the canopy and

92 counted as many acorns as they could in $15 \mathrm{~s}$ (Koenig et al. 1994a). Counts were then added, 
93 yielding the number of acorns per $30 \mathrm{~s}$ (N30). For all analyses, values were $\ln$-transformed ( $\ln$

$94[\mathrm{~N} 30+1]=\mathrm{LN} 30)$ to reduce the correlation between the mean and the variance.

96 Data analysis

97 In order to determine the effects of fire on acorn production, we constructed a series of

98 linear mixed-effects models for each species. "Year" was included as a categorical fixed effect in

99 all models in order to account for interannual variation. Random effects were generally "tree ID"

100 nested within "site," except for the analysis of differences among sites, in which "site" was

101 included as a categorical fixed effect and "tree ID" was included as a random effect. We used

102 mixed models with "tree ID" as a random effect because of the repeated measures experimental 103 design.

104 To examine the potential effects of site and fire frequency on acorn production, we first

105 modeled the effects of site and year on acorn production. Second, we examined the effect of

106 prescribed burns on acorn production in the year of the burn. We categorized each "tree $\mathrm{x}$ year"

107 combination as either "burned" or "not burned" and tested the effect of this factor on acorn

108 production along with the main effect of year.

109 Third, we examined the one-year time-lagged effects of prescribed burns on acorn

110 production. To do this, we assigned each "tree $\mathrm{x}$ year" combination a categorical variable

111 reflecting whether it was burned in the focal year $t$ (yes or no) and whether it was burned in the

112 previous year $t-1$ (yes or no). This yielded four categories: not burned in year $t$ or year $t-1$;

113 burned in year $t$ but not year $t-1$; not burned in year $t$ but burned in year $t-1$; and burned in

114 both year $t$ and year $t-1$ (sample sizes are listed in Figures 3a and 3b). We then tested the effects

115 of this variable on acorn production in year $t$, again including year in the analysis. 
116 Because pin oaks require two growing seasons to mature acorns, we also investigated

117 two-year time-lagged effects of burns on acorn production in this species. Similarly to the one

118 year time-lag analysis, we assigned each tree $\mathrm{x}$ year combination a categorical variable reflecting

119 whether or not a tree was burned in years $t, t-1$, and $t-2$, where $t$ is the focal year. Thus, there

120 were eight possible permutations of the variable. We again used a linear mixed model with the

121 main effects of the two-year time-lagged variable and year with acorn production in year $t$ as the

122 response variable. Although we report results of this model only for pin oaks, we also ran the

123 model for bur oaks and confirmed that the results were consistent with the one-year time-lag

124 analysis.

125 Except where noted, values reported are mean effect sizes \pm standard error in the natural

$126 \log$ scale of the response variable. All analyses were performed in R 2.14.0 (R Development

127 Core Team 2011).

129 Results

130 Comparisons among sites failed to reveal systematic effects of fire frequency on acorn

131 production for either species. For bur oak, no site had a significantly different pattern of acorn

132 production $(P>0.05$ for all sites). For pin oak, significantly lower acorn production was found in

133 site 113 ( 1 fire in 17 years; effect size $=-0.61 \pm 0.24 ; P=0.015$ ), but otherwise there were no

134 significant differences among the sites.

135 In both species, prescribed burns reduced acorn production (bur oak: effect size $=-0.20 \pm$

$1360.08 ; P=0.015$; Fig. 2a; pin oak: effect size $=-0.18 \pm 0.09 ; P=0.045$; Fig. 2b). Bur oak

137 exhibited significantly increased acorn production the year following a prescribed burn (effect

138 size $=0.35 \pm 0.09 ; P=0.0001$; Fig. 3a), even if the tree was burned again in the focal year 
139 (effect size $=0.38 \pm 0.13 ; P=0.004$; Fig. 3a). A prescribed burn the year following a "not

140 burned" year, however, significantly reduced acorn production (effect size $=-0.21 \pm 0.10 ; P=$

$1410.04)$

142 In contrast to the pattern found in bur oak, there were no one-year time-lagged effects on

143 acorn production in pin oak (Fig. 3b), even though the difference between the first two

144 treatments was similar in size to that of the model treating burns as a binary variable (Fig. 2b).

145 Furthermore, the two-year time-lagged analysis indicated that only one of the eight possible

146 iterations of the variable had a significant effect on acorn production by pin oaks, namely

147 reduced acorn production when trees were not burned in year $t-2$ but were burned in both years

$148 t-1$ and the focal year $t$ (effect size $=-0.45 \pm 0.19 ; P=0.016$ ).

150 Discussion

151 Previous studies support the assumption that prescribed burns, by reducing investment in

152 current fruit production, enhance both nutrients and carbohydrates subsequently available to the

153 trees (Goldschmidt and Golomb 1982; Weinbaum et al. 1994; Choi and Kang 2007; Crone et al.

154 2009). Furthermore, low level burns are known to increase soil nutrients and enhance foliar

155 nutrient concentrations (White et al. 1973; Schoch and Binkley 1986; Boerner et al. 1988; Gray

156 and Dighton 2006). Thus, although we did not directly measure nutrients or carbohydrates, the

157 pattern of controlled burns implemented during the study is likely to have had a strong influence

158 on the resource dynamics of the trees.

159 Assuming this was the case, our results are consistent with the hypothesis that stored

160 resources play a key role in the masting patterns of these tree species. Particularly persuasive

161 evidence comes from the contrasting results found for bur and pin oaks. As predicted, only bur 
162 oak, a species with highly variable acorn production typical of masting, exhibited increased

163 acorn production the year after the acorn crop was significantly depressed by burning. Acorn

164 production in pin oak, which reproduces nearly every year, was not enhanced either one or two

165 years following burns.

166 These results are consistent with the hypothesis that costs of reproduction in masting

167 plants are paid in terms of future reproduction. It could be fruitful in future research to compare

168 resource allocation dynamics of masting and non-masting plants to further test the stored

169 resource hypothesis. Masting plants may have a unique pattern of resource storage and depletion

170 leading to highly variable seed production, or these storage dynamics may be common patterns

171 that act in concert with a synchronizing cue to produce what we observe as masting.

172 The influence of weather could potentially confound our results or provide alternative

173 explanations. For example, there were late spring frosts in 1995 and 1999, which coincided with

174 near total crop failures in the bur oaks. However, prior work has found that acorn production

175 during the course of this study was primarily correlated with summer, rather than spring weather

176 (Koenig and Knops 2014). Furthermore, the trees in our study were distributed among sites that

177 experienced prescribed burns in different years and at various frequencies. Therefore, while all

178 of the trees were within a few kms of each other and experienced essentially the same weather in

179 every year, they differed in the pattern of burning to which they were subjected. Thus, although

180 weather factors may have increased the statistical noise in our analyses, they are unlikely to have

181 introduced any systematic biases.

182 Our study corroborates some previous research on alternate bearing (analogous to

183 masting) in orchard trees, which has demonstrated that resources accumulate during "off years"

184 where there is little or no fruit production, and are depleted by mass fruit production in "on 
185 years" (Goldschmidt and Golomb 1982; Weinbaum et al. 1994; Rosecrance et al. 1998).

186 Although several studies have provided some support for the importance of stored resources to

187 masting behavior, few prior studies have included a comparison with what amounts to a non-

188 masting control (Ichie et al. 2013; Crone and Rapp 2014).

189 There are two major issues that limit our understanding of the importance of stored

190 resources to masting behavior. First, both stored carbohydrates and stored mineral nutrients have

191 been investigated simultaneously in very few taxa. However, mounting evidence suggests that

192 the relevant limiting resource currency is specific to species, and possibly habitat (Goldschmidt

193 and Golomb 1982; Crone et al. 2009; Ichie and Nakagawa 2013; Sala et al. 2012). Second,

194 empirical research on the stored resource hypothesis has typically been short-term. This is

195 particularly relevant to wild tree populations that experience considerable environmental

196 heterogeneity. While our study did not directly measure stored resources, it is one of the few

197 long-term studies to address this issue.

198 Another aspect of our results that remains incompletely explained is the mechanism by

199 which low-level prescribed burns reduce current year acorn production. Peter et al. (2011) found

200 that burned Q. garryana stands suffered damaged buds and flowers, but this was only partly

201 attributable to the heating effects of the fire. In our study, both focal species exhibited reduced

202 acorn production in years plots were burned. However, controlled burns took place prior to

203 budburst, and thus the flowers of the two species would have been in very different stages when

204 burning occurred. For bur oak, a 1-year species that matures acorns in a single growing season,

205 the flowers for the autumn's acorn crop would have been in the bud stage. For pin oak, a 2-year

206 species that requires two growing seasons to mature acorns, the flowers for the current year's

207 acorn crop would have been present since the previous year, and the flowers for the next year's 
208 acorn crop would have been in the bud stage. The fact that acorn production by pin oak the year

209 following a burn was not affected suggests one of two possibilities: either the burns did not affect

210 the buds of the two species in the same way, or the burns did not mechanically affect the buds at

211 all and some other process reduced acorn production the year of burns. Our finding that bur oak

212 exhibited enhanced acorn production in years following a burn, even if it was burned a second

213 time, supports the latter hypothesis. Additional work on this issue is clearly warranted.

214 In conclusion, our work provides empirical evidence consistent with the hypothesis that

215 stored resources play an important role in masting behavior, a result that counters the null

216 hypothesis that masting is driven solely by differences in annual availability of resources (the

217 "resource tracking" hypothesis; Kelly and Sork 2002). In particular, our evidence suggests that

218 masting intensity varied in tandem with resource storage across two sympatric species, one of

219 which is a masting species that exhibits high annual variability in acorn production while the

220 other does not. Seed production of masting species can have cascading effects on wildlife

221 populations (Jones et al. 1998; Ostfeld and Keesing 2000; Koenig and Knops 2005; Clotfelter et

222 al. 2007), and thus environmental factors such as fire frequency that influence resource

223 availability can play potentially important roles in ecosystem dynamics.

225 Acknowledgements

226 We thank the late John Haarstad for help selecting sites and the Cedar Creek Ecosystem

227 Research Center for maintaining the burning treatments and the reviewers for their comments.

228 Partial support for this project came from the National Science Foundation, most recently

229 through grant DEB-0816691 to WDK and Cedar Creek NSF LTER. 


\section{References}

232 Boerner, R.E.J., Lord, T.R., and Peterson, J.C. 1988. Prescribed Burning in the Oak-pine Forest

233 of the New Jersey Pine Barrens: Effects on Growth and Nutrient Dynamics of Two Quercus

234 Species. American Midland Naturalist 120(1): 108-119.

235 Chapin, F.S.I., Schulze, E.-D., and Mooney, H.A. 1990. The ecology and economics of storage

236 in plants. Annual Review of Ecology and Systematics 21(ArticleType: research-article / Full

237 publication date: 1990 / Copyright (C) 1990 Annual Reviews): 423-447.

238 Choi, S.-T., and Kang, S.-M. 2007. Effects of defoliation and defruiting in early September on

239 partitioning of nonstructural carbohydrates in 'Fuyu' persimmon at harvest. Horticulture,

240 Environment and Biotechnology 48(6): 359-364.

241 Clotfelter, E., Pedersen, A., Cranford, J., Ram, N., Snajdr, E., Nolan, V., and Ketterson, E. 2007.

242 Acorn mast drives long-term dynamics of rodent and songbird populations. Oecologia 154(3):

243 493-503. doi: 10.1007/s00442-007-0859-z.

244 Crone, E.E., Miller, E., and Sala, A. 2009. How do plants know when other plants are flowering?

245 Resource depletion, pollen limitation and mast-seeding in a perennial wildflower. Ecology

246 Letters 12(11): 1119-1126. doi: 10.1111/j.1461-0248.2009.01365.x.

247 Crone, E.E., Polansky, L., and Lesica, P. 2005. Empirical Models of Pollen Limitation, Resource

248 Acquisition, and Mast Seeding by a Bee-Pollinated Wildflower. The American Naturalist 166(3):

249 396-408. doi: doi:10.1086/432561.

250 Crone, E.E., and Rapp, J.M. 2014. Resource depletion, pollen coupling, and the ecology of mast

251 seeding. Annals of the New York Academy of Sciences 1322(1): 21-34. doi:

$25210.1111 /$ nyas. 12465. 
253 Goldschmidt, E.E., and Golomb, A. 1982. The carbohydrate balance of alternate-bearing citrus

254 trees and the significance of reserves for flowering and fruiting. J. Amer. Soc. Hort. Sci 107(2):

$255 \quad 206-208$.

256 Gray, D.M., and Dighton, J. 2006. Mineralization of forest litter nutrients by heat and

257 combustion. Soil Biology and Biochemistry 38(6): 1469-1477. doi:

$258 \quad 10.1016 /$ j.soilbio.2005.11.003.

259 Harper, J.L. 1977. Population biology of plants. Academic Press, London, U.K.

260 Hoch, G., Siegwolf, R.W., Keel, S., Körner, C., and Han, Q. 2013. Fruit production in three

261 masting tree species does not rely on stored carbon reserves. Oecologia 171(3): 653-662. doi:

$26210.1007 / \mathrm{s} 00442-012-2579-2$.

263 Ichie, T., Igarashi, S., Yoshida, S., Kenzo, T., Masaki, T., and Tayasu, I. 2013. Are stored

264 carbohydrates necessary for seed production in temperate deciduous trees? Journal of Ecology

265 101(2): 525-531. doi: 10.1111/1365-2745.12038.

266 Ichie, T., Kenzo, T., Kitahashi, Y., Koike, T., and Nakashizuka, T. 2005. How does

267 Dryobalanops aromatica supply carbohydrate resources for reproduction in a masting year?

268 Trees - Structure and Function 19(6): 704-711. doi: 10.1007/s00468-005-0434-3.

269 Ichie, T., and Nakagawa, M. 2013. Dynamics of mineral nutrient storage for mast reproduction

270 in the tropical emergent tree Dryobalanops aromatica. Ecological Research 28(2): 151-158. doi:

$271 \quad 10.1007 / \mathrm{s} 11284-011-0836-1$.

272 Isagi, Y., Sugimura, K., Sumida, A., and Ito, H. 1997. How Does Masting Happen and

273 Synchronize? Journal of Theoretical Biology 187(2): 231-239.

274 Jones, C.G., Ostfeld, R.S., Richard, M.P., Schauber, E.M., and Wolff, J.O. 1998. Chain reactions

275 linking acorns to gypsy moth outbreaks and Lyme disease risk. Science 279(5353): 1023-1026. 
276 Kelly, D., and Sork, V.L. 2002. Mast Seeding in Perennial Plants: Why, How, Where? Annual 277 Review of Ecology and Systematics 33: 427-447.

278 Knops, J.M.H., Koenig, W.D., and Carmen, W.J. 2007. Negative correlation does not imply a 279 tradeoff between growth and reproduction in California oaks. Proceedings of the National 280 Academy of Sciences 104(43): 16982-16985. doi: 10.1073/pnas.0704251104.

281 Koenig, W., and Knops, J.H. 2014. Environmental correlates of acorn production by four species 282 of Minnesota oaks. Popul Ecol 56(1): 63-71. doi: 10.1007/s10144-013-0408-z.

283 Koenig, W.D., and Knops, J.M.H. 1998. Scale of mast-seeding and tree-ring growth. Nature 284 396(6708): 225-226.

285 Koenig, W.D., and Knops, J.M.H. 2005. The Mystery of Masting in Trees. American Scientist 286 93(4): 340-.

287 Koenig, W.D., Knops, J.M.H., Carmen, W.J., Stanback, M.T., and Mumme, R.L. 1994a.

288 Estimating acorn crops using visual surveys. Canadian Journal of Forest Research 24(10): 2105289 2112. doi:10.1139/X94-270.

290 Koenig, W.D., Mumme, R.L., Carmen, W.J., and Stanback, M.T. 1994b. Acorn production by 291 oaks in central coastal California: Variation within and among years. Ecology 75(1): 99.

292 Kon, H., Noda, T., Terazawa, K., Koyama, H., and Yasaka, M. 2005. Evolutionary advantages of 293 mast seeding in Fagus crenata. Journal of Ecology 93(6): 1148-1155. doi: 10.1111/j.1365$294 \quad 2745.2005 .01040 . x$.

295 Kozlowski, T., and Keller, T. 1966. Food relations of woody plants. The Botanical Review 296 32(4): 293-382. doi: 10.1007/bf02858663.

297 Miyazaki, Y. 2013. Dynamics of internal carbon resources during masting behavior in trees. 298 Ecological Research 28(2): 143-150. doi: 10.1007/s11284-011-0892-6. 
299 Miyazaki, Y., Hiura, T., Kato, E., and Funada, R. 2002. Allocation of Resources to Reproduction 300 in Styrax obassia in a Masting Year. Annals of Botany 89(6): 767-772. doi: 10.1093/aob/mcf107.

301 Norton, D.A., and Kelly, D. 1988. Mast Seeding Over 33 Years by Dacrydium cupressinum

302 Lamb. (rimu) (Podocarpaceae) in New Zealand: The Importance of Economies of Scale.

303 Functional Ecology 2(3): 399-408.

304 Ostfeld, R.S., and Keesing, F. 2000. Pulsed resources and community dynamics of consumers in 305 terrestrial ecosystems. Trends in Ecology \& Evolution 15(6): 232-237.

306 Peter, D., Agee, J., and Sprugel, D. 2011. Effects of prescribed burning on leaves and flowering

307 of Quercus garryana. Trees - Structure and Function 25(4): 679-688. doi: 10.1007/s00468-011$308 \quad 0545-\mathrm{y}$

309 Peterson, D.W., and Reich, P.B. 2001. Prescribed fire in oak savanna: fire frequency effects on 310 stand structure and dynamics. Ecological Applications 11(3): 914-927. doi: 10.1890/1051-

311 0761(2001)011[0914:pfiosf]2.0.co;2.

312 Rapp, J.M., and Crone, E.E. 2015. Maple syrup production declines following masting. Forest

313 Ecology and Management 335: 249-254. doi: http://dx.doi.org/10.1016/j.foreco.2014.09.041.

314 Roff, D.A. 2002. Life History Evolution. Sinauer Associates, Sunderland, MA.

315 Rosecrance, R.C., Weinbaum, S.A., and Brown, P.H. 1998. Alternate bearing affects nitrogen,

316 phosphorus, potassium and starch storage pools in mature pistachio trees. Annals of Botany

317 82(4): 463-470. doi: 10.1006/anbo.1998.0696.

318 Sala, A., Hopping, K., McIntire, E.J.B., Delzon, S., and Crone, E.E. 2012. Masting in whitebark

319 pine (Pinus albicaulis) depletes stored nutrients. New Phytologist: no-no. doi: 10.1111/j.1469-

$320 \quad 8137.2012 .04257 . x$. 
321 Satake, A., and Bjørnstad, O. 2008. A resource budget model to explain intraspecific variation in 322 mast reproductive dynamics. Ecological Research 23(1): 3-10. doi: 10.1007/s11284-007-0397-5.

323 Satake, A., and Iwasa, Y. 2002. The synchronized and intermittent reproduction of forest trees is 324 mediated by the Moran effect, only in association with pollen coupling. Journal of Ecology

325 90(5): 830-838. doi: 10.1046/j.1365-2745.2002.00721.x.

326 Schoch, P., and Binkley, D. 1986. Prescribed burning increased nitrogen availability in a mature

327 loblolly pine stand. Forest Ecology and Management 14(1): 13-22. doi: 10.1016/0378-

$328 \quad 1127(86) 90049-6$.

329 Silvertown, J.W. 1980. The evolutionary ecology of mast seeding in trees. Biological Journal of 330 the Linnean Society 14(2): 235-250. doi: 10.1111/j.1095-8312.1980.tb00107.x.

331 Smaill, S.J., Clinton, P.W., Allen, R.B., and Davis, M.R. 2011. Climate cues and resources

332 interact to determine seed production by a masting species. Journal of Ecology 99(3): 870-877.

333 Sork, V.L., Bramble, J., and Sexton, O. 1993. Ecology of Mast-Fruiting in Three Species of

334 North American Deciduous Oaks. Ecology 74(2): 528-541.

335 R Development Core Team. 2011. R: A language and environment for statistical computing. R

336 Foundation for Statistical Computing, Vienna, Austria. URL http://www.R-project.org.

337 Weinbaum, S., Niederholzer, F., Ponchner, S., Rosecrance, R., Carlson, R., Whittlesey, A., and

338 Muraoka, T. 1994. Nutrient uptake by cropping and defruited field-grown French prune trees.

339 Journal of the American Society for Horticultural Science 119(5): 925-930.

340 White, E.M., Thompson, W.W., and Gartner, F.R. 1973. Heat effects on nutrient release from

341 soils under ponderosa pine. Journal of Range Management 26(1): 22-24. 
Table 1. Summary of fire frequencies and sample sizes at each study site with the number of trees remaining in 2011 in brackets.

\begin{tabular}{cccc}
\hline $\begin{array}{c}\text { Site } \\
\text { ID }\end{array}$ & $\begin{array}{c}N \text { fires } \\
\text { (out of } 17 \text { yrs) }\end{array}$ & $\begin{array}{c}N \text { trees } \\
\text { (bur oak) }\end{array}$ & $\begin{array}{c}N \text { trees } \\
\text { (pin oak) }\end{array}$ \\
\hline 104 & 12 & $15[13]$ & $15[8]$ \\
105 & 9 & $15[11]$ & $15[6]$ \\
107 & 6 & $15[14]$ & $15[11]$ \\
110 & 0 & $15[15]$ & $15[13]$ \\
113 & 2 & $15[15]$ & $15[11]$ \\
116 & 6 & $15[14]$ & $14[14]$ \\
\hline
\end{tabular}




\section{Figure captions}

Figure 1. Annual population mean natural log-transformed acorn counts for bur oaks (gray bars) and pin oaks (black bars). Error bars represent \pm 1 standard error. There is no column for bur oaks in 1995 because of a total acorn crop failure throughout the study population.

Figure 2. Natural log-transformed acorn counts for trees that did not experience a controlled burn ('not burned') vs. those that did ('burned'). All 'tree x year' combinations are included. Tukey's notches on the boxplots indicate the median $\pm 1.58 \frac{I Q R}{\sqrt{N}}$, where $I Q R$ is the interquartile range and $N$ is the sample size. (a) bur oak data ( $\mathrm{N}$ for each treatment from left to right is 1012 and 466), and (b) pin oak data ( $\mathrm{N}$ for each treatment from left to right is 941 and 393). $* P<0.05$.

Figure 3. Natural log-transformed acorn counts in year $t$ for each one-year time-lag variable, where 'yes' or 'no' indicates whether trees were burned or not burned in year $t$ (focal year) and year $t-1$ (previous year). Tukey's notches on the boxplots indicate the median $\pm 1.58 \frac{10 R}{\sqrt{N}}$, where $I Q R$ is the interquartile range and $N$ is the sample size. (a) bur oak data ( $\mathrm{N}$ for each treatment from left to right is 698, 297, 314, and 169), and (b) pin oak data ( $\mathrm{N}$ for each treatment from left to right is $660,258,281$, and 135), $* P<0.05$, ** $P<0.01$, *** $P<0.001$. 


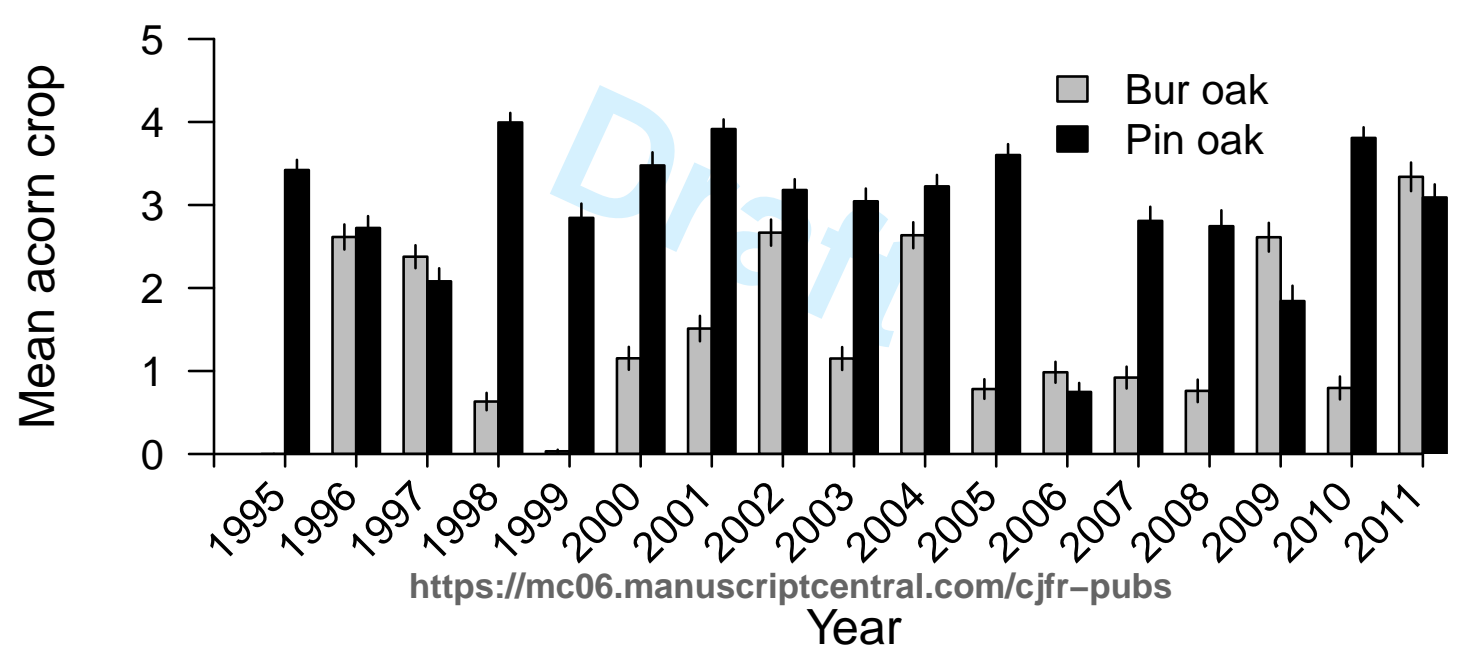




\section{Bur oak}

\section{Pin oak}
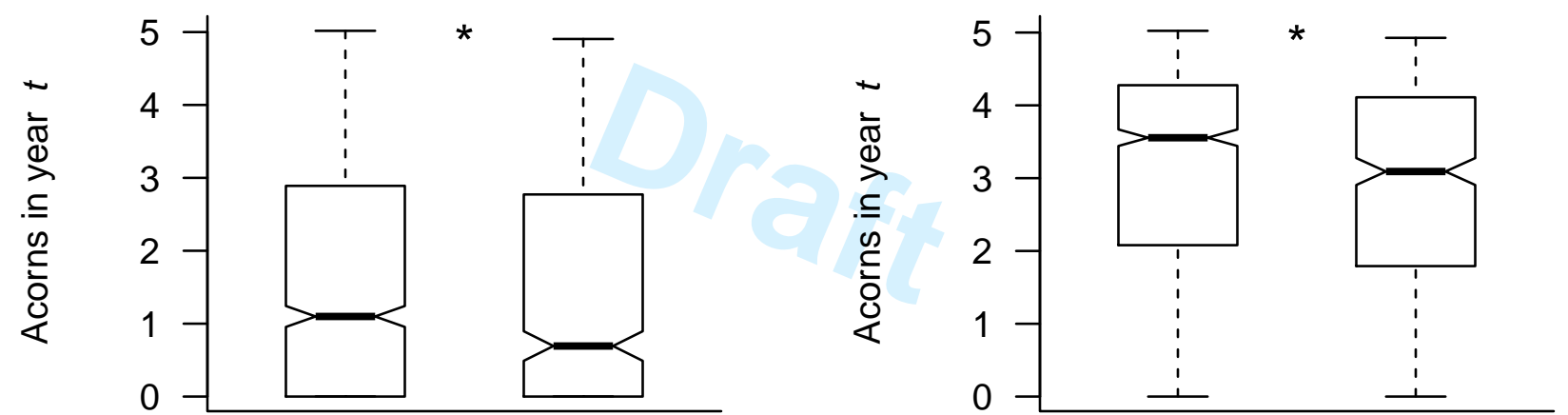

not burned

burned

not burned

burned

https://mc06.manuscriptcentral.com/cjfr-pubs Burned or not in year $t$ 
a)

Canadian Journal of Forest Research Bur oak
Page 22 of 22

\section{Pin oak}
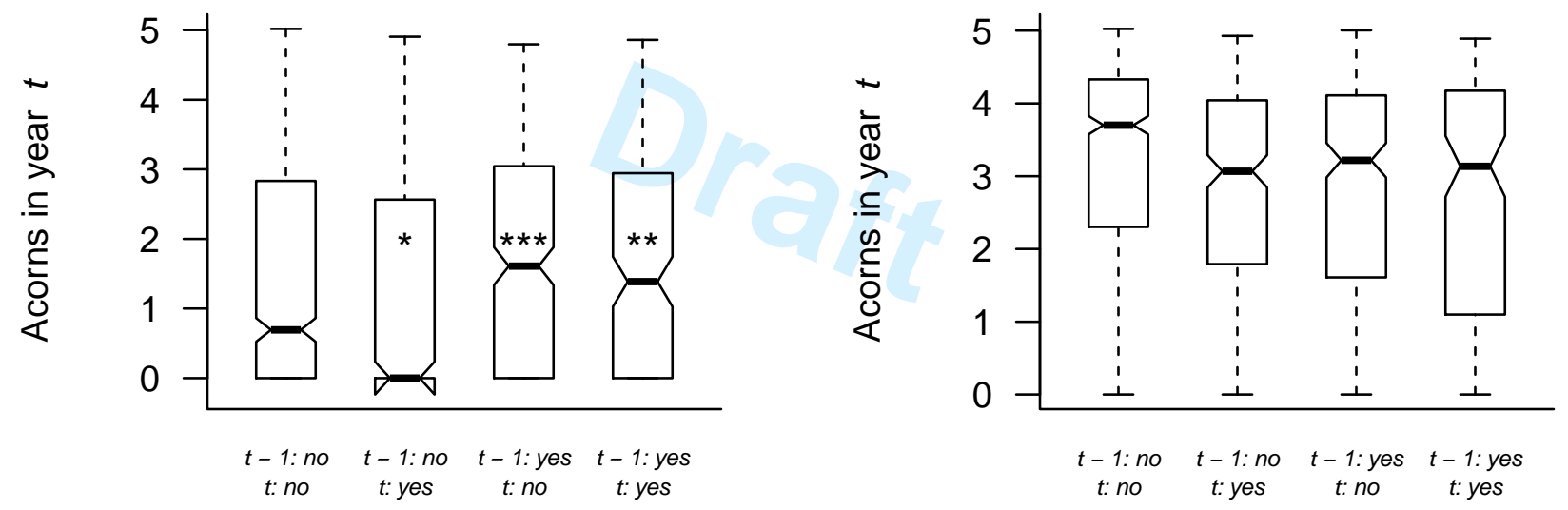

https://mc06.manuscriptcentral.com/cjfr-pubs

Burns in years $t-1$ and $t$

Burns in years $t-1$ and $t$ 